\title{
ECOLOGICAL EFFICIENCY ASSESSMENT MODEL FOR ENVIRONMENTAL SAFETY MANAGEMENT OF WIND POWER PLANT
}

doi: $\quad 10.2478 /$ czoto-2019-0047

Date of submission of the article to the Editor: 30/11/2018

Date of acceptance of the article by the Editor: 23/01/2019

Robert Kasner ${ }^{1}$ - orcid id: 0000-0001-6866-4741

Józef Flizikowski ${ }^{1}$ - orcid id: 0000-0001-7264-7776

Andrzej Tomporowski ${ }^{1}$ - orcid id: 0000-0002-9860-8748

Weronika Kruszelnicka ${ }^{1}$ - orcid id: 0000-0002-9909-5112

Adam Idzikowski ${ }^{2}$ - orcid id: 0000-0003-1178-8721

${ }^{1}$ University of Science and Technology in Bydgoszcz, Poland

${ }^{2}$ Czestochowa University of Technology, Poland, adam.idzikowski@wz.pcz.pl

Abstract: This study focuses on the evaluation of the benefits and ecological costs that occur in the life cycle of a wind power plant. The study constitutes an attempt to expand upon previously conducted research on the analysis of costs and benefits in the stages of production, operation and post-consumer management of wind turbines. The aim of the study adopted research methodology, analysis and assessment of the benefits and environmental impacts of the Vestas V90/105m 2 MW wind turbine throughout its life cycle. Original assessment indicators of the benefits and ecological costs occurring throughout a wind power plant's life cycle for environmental safety management, were proposed and verified.

Keywords: wind power plant, ecological efficiency, renewable energy, emission in life cycle

\section{INTRODUCTION}

Few experimental and analytical studies have been devoted to the benefits and costs characterizing the entire life cycle of a wind power plant (Brondsted et al., 2005; Conconi, 2012; Kasner et al., 2015; Kasner, 2016; Tomporowski et al., 2018). All the life cycle stages of a wind power plant have great importance for the economy and environment. These stages include its design and production as well as postconsumer management of its potential as a source of raw materials, plastics, and other materials (sometimes the entire assembly may be used for further use, such as with the tower or gear unit) (Alberts, 2009; Bovea and Powell, 2006; Flizikowski et al. 2018). It is worth undertaking comprehensive research that is analytical and experimental to determine the benefits and impacts arising from the life cycle of a wind power plant. To be assessed is whether the power and electricity generating benefits of a wind power plant's functioning together with the use-phases's reduction 
in greenhouse gas emissions exceed the environmental costs in the form of energy used and greenhouse gas emitted in all stages of a wind power plant's life cycle (Tomporowski et al., 2017a; Tomporowski et al., 2017b).

The main aim of this study is to develop a research methodology of the benefits and ecological costs of a wind power plant's life cycle ranging from its production and safer use to the management of its potential in terms of raw materials, plastics, and post-consumer materials.

\section{BENEFITS AND COSTS OF A WIND POWER PLANT'S LIFE CYCLE}

The life cycle of a wind power plant consists of five successive stages: the formulation of need (FN), design/construction (C), production (P), use (U) and post-consumer management (CM), ending the cycle of its existence (Flizikowski et al., 2015, Garrett and Rendc 2013, Macko et al., 2017).

The environmental benefit in the life cycle of the wind power plant is the production of power and energy during the use-stage. These benefits depend primarily on the windiness of a given area as well as the type of wind power plant in question. For the use-phase, average speeds are of great importance, but information and models of seasonal wind variability, based on multiple years of measurements and observations, are equally important. The surest strategy to determine a given wind power plant's productivity is to conduct a methodical, operational test of an actually functioning object of this kind (Tomporowski et al., 2017a).

An assessment of the environmental impacts of a wind power plant's life cycle can be made by making use of LCA analysis (Berg 1997; Garrett and Rendc 2013). The LCA model serves to quantitatively measure the environmental impact of technical objects in general and, in the entire life cycle of a wind power plant in particular, serves to measure the emission of harmful compounds and the quantitative consumption of materials (Andersson et al., 1998; Goedkoop et al., 2010; Guinee and Gorrree 2002).

\subsection{A model of an integrated indicator of benefits and costs}

At the foundation of a proper analysis and assessment of a given source of energy's benefits and costs is the need to take into account its entire life cycle. To assess the operation of a wind power plant throughout its life cycle, the following integrated efficiency indicator was defined and proposed (Kasner 2016):

$$
E(t)=\frac{U(t)}{N(t)}
$$

where:

$E(t)$ - integrated efficiency indicator during t years of use throughout the life cycle of a wind power plant,

$U(t)$ - the benefits throughout the life cycle of a wind power plant,

$N(t)$ - costs throughout the life cycle of a wind power plant,

$t$ - time of use of the wind power plant.

With the following additional definitions:

$U_{i}$ - benefits during a given year of use,

$N_{W}$ - costs at the production stage,

$N_{i}$ - costs during a given year of use,

$N_{Z}$ - costs during post-consumer management, it can be accepted that: 


$$
E(t)=\frac{U(t)}{N(t)}=\frac{\sum_{i=1}^{i} U_{i}}{N_{w}+\sum_{i=1}^{i} N_{i}+N_{z}}
$$

\subsection{Analysis of the integrated indicator of benefits from costs incurred}

The relationship of the integrated indicator of benefits from costs incurred from the beginning of use has the nature of a homographic function. Figure 1 presents model courses of the integrated efficiency indicator in the function of time-of-use for two different ways of post-consumer management, namely landfilling and recycling.

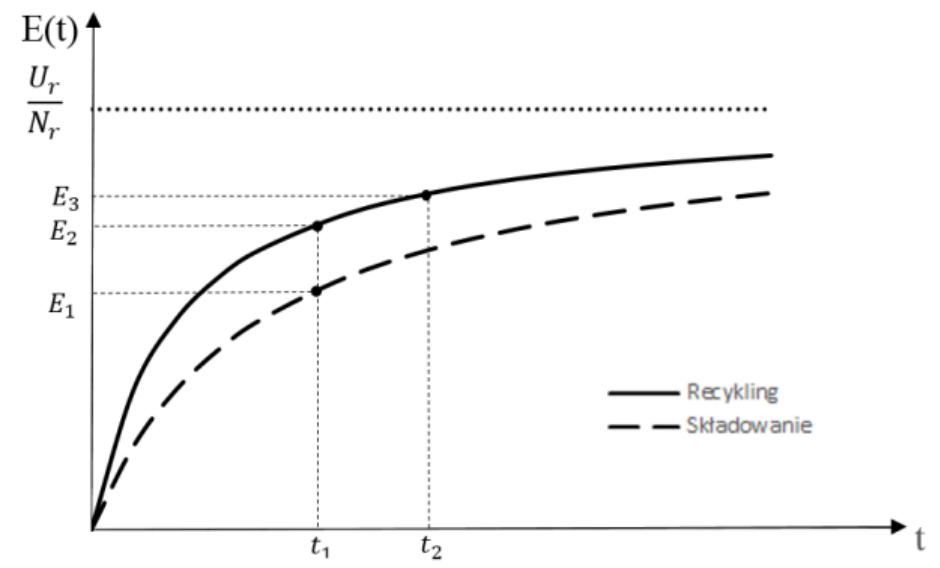

Fig. 1. Graph of the integrated efficiency indicator in the function of time of use [developed by the authors on the basis of (Kasner, 2016)]

For the courses presented in figure 1, it was assumed that costs at the post-consumer management stage in the case of landfilling are higher than the recycling costs at the post-consumer management stage. In this situation, for the same time of use, the integrated efficiency indicator for recycling is higher than for landfilling $\left(E_{2}>E_{1}\right)$. From the courses presented it may be understood that when time of use is extended $\left(t_{2}>t_{1}\right)$, the value of the integrated efficiency indicator grows $\left(E_{3}>E_{2}\right)$ (Kasner, 2016).

From the analysis it follows that there exists a cause-effect relationship between the integrated efficiency indicator and the method of post-consumer management and time of use. The threshold of the integrated efficiency indicator for $t \rightarrow+\infty$, or in other words, the horizontal asymptote in the chart, is the value of the quotient of average annual benefits $U_{r}$ divided by average annual costs at the use-stage $N_{r}$. The threshold of the indicator being analyzed does not depend on the method of postconsumer management (Kasner, 2016).

The dependence of the integrated efficiency indicator on the average annual benefits achieved has the nature of a linear function. Figure 2 presents model courses of the integrated efficiency indicator in the function of average annual benefits for two different times of use $t_{1}$ and $t_{2}$. The values $U_{r p}$ and $U_{r k}$ indicate the most probable range of annual productivity (Kasner, 2016).

It follows from the courses presented in figure 2, just as with the courses presented in figure 1, that increasing the time of use $\left(t_{2}>t_{1}\right)$ results in an increase of the integrated efficiency indicator $\left(E_{2}>E_{1}\right)$ and a change in its profile in the average annual benefits 
function. In this situation, an increase of average annual benefits $\left(U r_{2}>U r_{1}\right)$ results in an increase of the integrated efficiency indicator as well $\left(E_{3}>E_{1}\right)$ (Kasner, 2016).

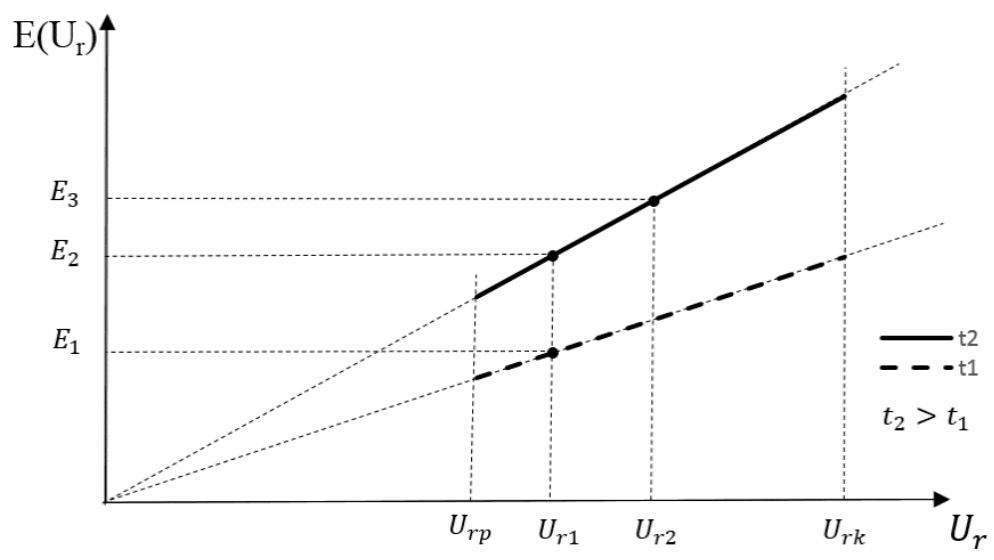

Fig. 2. Graph of the integrated efficiency indicator in the function of average annual benefits [developed by the authors on the basis of (Kasner, 2016)]]

The proposed model of the integrated efficiency indicator is the right tool to analyze and assess the ecological impacts and benefits of high-power wind power plants throughout their life cycle. It enables comparisons to be made of designed and existing energy sources based on analytical experiment.

\subsection{Integrated indicator of benefits from ecological costs}

When desiring to define the indicator of benefits from incurred ecological costs throughout the life cycle, we will use the integrated efficiency indicator. Ecological benefits arising from the operation of a wind power plant were defined as the electrical energy generated throughout its life cycle.

Ecological costs arising from the operation of a wind power plant were defined depending on the reference point accepted:

- Taking the impact of the average European on the environment as an ecological cost, the LCA method, and in particular the eco-indicator 99 model, gives us, in environmental points, a wind power plant's resulting impact on its surroundings throughout its whole life cycle, where 1000 pts corresponds with the impact of one European on the environment during one year.

- When analyzing $\mathrm{CO}_{2 \mathrm{eq}}, \mathrm{SO}_{2 \mathrm{eq}}, \mathrm{PO}_{4 \mathrm{eq}}$ emissions and taking them as ecological costs, IPCC, eco-indicator 99, and CML modeling allows one to determine the size of greenhouse gas emissions as well as the size of substances causing acidification or eutrophication of the environment throughout the whole life cycle of a wind power plant.

- If social aspects are a reference point, we may, giving them the appropriate weight, accept as social costs all human habitats existing at the power and energy generation stage falling within a wind power plant's radius of impact:

$$
N S=\sum_{i=1}^{n} L P_{i} \cdot w_{i}
$$

$N S$ - social costs arising from the wind power plant's existence,

$L P_{i}-$ number of human habitats within a given distance from the wind power plant, $w_{i}$ - weight of a given human habitat. 
A human habitat is defined as a single-family house or as the number of families in a multi-family house. Given that the exponential function often describes social and environmental phenomena, location weight was defined:

$$
w_{i}=\exp \left(-\frac{r_{i}}{R}\right)
$$

where:

$r_{i}$ - distance of a given human habitat from the wind power plant,

$R$ - assumed impact radius of the wind power plant.

Assuming the threshold weight of a human habitat as $w_{g r}$, on the basis of (4) we may define the radius of threshold social costs around a wind power plant $r_{g r}$ as:

$$
r_{g r}=-R \ln w_{g r}
$$

To perform an ecological assessment of the existence and operation of a wind power plant, an indicator of benefits from ecological costs arising throughout the wind power plant's life cycle was formulated. Ecological costs include: emissions of greenhouse gases, emissions of substances causing acidification, emissions of substances causing eutrophication, and social costs.

Below the examples of formulas describing the aforementioned indicators are presented.

\section{Integrated indicator of ecological benefits from ecological costs}

$$
\begin{gathered}
E_{e c o_{E U}}=\frac{U(t)_{E}}{N(t)_{E U}} \\
N(t)_{E U}=N_{W E U}+N(t)_{U E U}+N_{Z E U} \\
N(t)_{U E U}=N_{r E U} \cdot t \\
U(t)_{E}=U_{r E} \cdot t \\
E_{e c 0_{E U}}=\frac{U(t)_{E}}{N_{W E U}+N(t)_{U E U}+N_{Z E U}}=\frac{U_{r E} \cdot t}{N_{W E U}+N_{r E U} \cdot t+N_{Z E U}}
\end{gathered}
$$

Respectively:

$U(t)_{E}$-usable energy generated during $t$ years of use,

$N(t)_{E U}$ - number of environmental points throughout a wind power plant's entire life cycle of use for $t$ years, where 1000 pts is equivalent to the environmental impact of one European during one year, $t$ - time of use,

$N_{W E U}-$ number of environmental points at the generation-stage,

$N_{U E U}-$ number of environmental points at the use-stage,

$N_{\text {ZEU }}$ - number of environmental points at the post-consumer management stage,

$N_{r E U}$ - average number of environmental points during one year at the use-stage,

$U_{r E}$ - average annual productivity at the use-stage.

Integrated indicators of emissions of greenhouse gases, emissions of substances causing acidification, emissions of substances causing eutrophication were made up in similar way taking into account appropriate ecological cost: $\mathrm{CO}_{2}$ emissions, $\mathrm{SO}_{2}$ emissions and $\mathrm{PO}_{4}$ emissions. 


\section{Integrated indicator of benefits from social costs}

$$
\begin{gathered}
E_{\text {ecoNS }}=\frac{U(t)_{E}}{N S(t)} \\
U(t)_{E}=U_{r E} \cdot t, \quad N S(t)=N S \cdot t, \quad w_{i}=\exp \left(-\frac{r_{i}}{R}\right) \\
E_{\text {ecoNS }}=\frac{U_{r E}}{\sum_{i=1}^{n} L P_{i} \cdot \exp \left(-\frac{r_{i}}{R}\right)}=\frac{U_{r E}}{N S}
\end{gathered}
$$

Respectively:

$U(t)_{E}$ - usable energy generated during $t$ years of use,

$N S$ - social costs arising from the existence of the wind power plant,

$t$ - time of use,

$L P_{i}-$ number of human habitats in a given distance from the wind power plant,

$w_{i}$ - weight of a given human habitat,

$n$ - number of human habitats analyzed which are affected by the power plant,

$r_{i}$ - distance of a given human habitat from the wind power plant,

$R$ - assumed impact radius of the wind power plant.

\section{CONCLUSIONS}

A research methodology for the assessment of the ecological costs and benefits of a wind power plant's life cycle was developed and tested, covering said power plant's production and safer use, as well as the management of its potential in terms of energy, raw materials, plastics, and post-consumer materials.

The proposed model of the integrated efficiency indicator is the right tool to analyze and assess the ecological impacts and benefits of high-power wind power plants throughout their life cycle. It enables comparisons to be made of designed and existing energy sources based on analytical experiment.

On the basis of analytical and experimental research and with reference to state-ofthe-art knowledge and practice in the design, operation, and post-consumer management of wind power plants, it should be acknowledged that our effort to describe, with a mathematical model, the relationship between the environmental benefits and incurred costs connected with the life cycle of a wind power plant, with focus on the productivity and time of use thereof, was justified.

It follows from the research analysis herein and from our own program of experimental, verificational research according to the indicators here accepted that it is possible to conduct detailed analysis of the benefits of the use of wind power plants with reference to real environmental costs arising from their operation and management.

\section{REFERENCES}

Alberts, H., 2009. Recycling of wind turbine rotor blades - fact or fiction? Dewi Magazin, 34(2), 32-41.

Andersson, K., Eide, M.H., Lundquist, U., Mattsson, B., 1998. The feasibility of including sustainability in LCA for product development. Journal of Cleaner Production, 6(3-4), 289-298, DOI:10.1016/S0959-6526(98)00028-6 
Berg, S., 1997. Some aspects of LCA in the analysis of forestry operations, Journal of Cleaner Production. 5(3), 211-217, DOI: 10.1016/S0959-6526(97)00040-1

Bovea, M., Powell, J., 2006. Alternative scenarios to meet the demands of sustainable waste management. Journal of Environmental Management, 79(2), 115-132, DOI: 10.1016/j.jenvman.2005.06.005

Brondsted, P., Lilholt, H., Aage, L., 2005. Composite materials for wind power turbine blades. Annual review of Materials Research, 35, 505-538, DOI: 10.1146/annurev.matsci.35.100303.110641

Conconi, M., 2012. Raport EWEA:Research note outline on recycling wind turbines blades. The European Wind Energy Association, Brussels, Belgium.

Flizikowski, J., Piasecka, I., Kruszelnicka, W., Tomporowski, A., Mroziński, A., 2018. Destruction assessment of wind power plastics blade. Polimery, 63(5), 381-386, DOI: dx.doi.org/10.14314/polimery.2018.5.7

Flizikowski, J., Sadkiewicz, J., Tomporowski, A., 2015. Functional characteristics of a six-roller mill for grainy or particle materials used in chemical and food industries. Przemysl Chemiczny, 94(1), (2015), 69-75, DOI:10.15199/62.2015.1.9.

Garrett, P., Rendc, K., 2013. Life cycle assessment of wind power: comprehensive results from a state-of-the-art approach. The International Journal of Life Cycle Assessment, 18(1), 37-48, DOI: doi.org/10.1007/s11367-012-0445-4

Goedkoop, M., Schryver, A., Oele, M., Roest, D., Vieira, M., Durksz, S., 2010. SimaPro 7. Tutorial. PRé Consultants, Netherlands

Guinee, J.B., Gorrree, M., 2002. Handbook on Life Cycle Assessment - Operational Guide to the ISO Standards. Kluwer Academic Publishers, Netherlands

Kasner, R., 2016. Assessment of benefits and investments for wind farm life cycle. Doctoral thesis, Poznan University of Technology, Poznań, Poland

Kasner, R., Piasecka, I., Piotrowska, K., Tomporowski, A., 2015. Application of CML method to evaluate the environmental impact of selected transportation of wind power plants blades. Logistyka, 3, 2102-2108,

Macko, M., Flizikowski, J., Szczepanski, Z., Tyszczuk, K., Śmigielski, G., Mrozinski, A., Czerniak, J., Tomporowski, A., 2017. CAD/CAE Applications in Mill's Design and Investigation. Proceedings of 13th International Scientific Conference: Computer Aided Engineering, Wrocław, Poland; 22-24 June 2017. Springer International Publishing, 343-351.

Tomporowski, A., Piasecka, I., Flizikowski, J., Kasner, R., Kruszelnicka, W., Mroziński, A., Bieliński, K., 2018. Comparison analysis of blade life cycles of landbased and offshore wind power plants. Polish Maritime Research, 25(SI1), 225233, DOI: 10.2478/pomr-2018-0046

Tomporowski, A., Flizikowski, J, Kasner, R., Kruszelnicka, W., 2017a. Environmental Control of Wind Power Technology. Rocznik Ochrona Środowiska, 19, 694-714.

Tomporowski, A., Flizikowski, J, Opielak, M., Kasner, R., Kruszelnicka, W., 2017b. Assessment of energy use and elimination of $\mathrm{CO} 2$ emissions in the life cycle of an offshore wind power plant farm. Polish Maritime Research, 24(4), 93-101, DOI: doi.org/10.1515/pomr-2017-0140 